\title{
BMJ Open Does time spent in the residential neighbourhood moderate the relationship between neighbourhood walkability and transport-related walking? a cross-sectional study from Toronto, Canada
}

\author{
Antony Chum, ${ }^{\oplus 1,2}$ Peter Atkinson, Patricia O'Campo ${ }^{2}$
}

To cite: Chum A, Atkinson $P$, O'Campo P. Does time spent in the residential neighbourhood moderate the relationship between neighbourhood walkability and transport-related walking? a cross-sectional study from Toronto, Canada. BMJ Open 2019;9:e23598. doi:10.1136/ bmjopen-2018-023598

- Prepublication history for this paper is available online To view these files, please visit the journal online (http://dx.doi org/10.1136/bmjopen-2018023598).

Received 23 April 2018 Revised 3 January 2019 Accepted 1 February 2019

Check for updates

(C) Author(s) (or their employer(s)) 2019. Re-use permitted under CC BY-NC. No commercial re-use. See rights and permissions. Published by BMJ.

${ }^{1}$ Department of Health Sciences, Brock University, Saint Catharines, Ontario, Canada ${ }^{2}$ St. Michael's Hospital, Toronto, Ontario, Canada

Correspondence to

Dr Antony Chum;

antony.chum@gmail.com

\section{ABSTRACT}

Objectives Studies have investigated the influence of neighbourhood walkability on residents' walking behaviour, aiming to increase physical activity and reduce dependence on automobiles. Previous research, however, has not considered how the amount of time spent in the residential neighbourhood may modify this relationship. Our objective was to determine how time spent in the residential neighbourhood affects the relationship between neighbourhood walkability and walking for transport.

Design Using a cross-sectional sample of 2411 adults, we analysed the association between walkability (an index combining land-use mix, dwelling density and street connectivity) and transport-related walking (controlling for the effects of gender, age, income, self-rated health and regular access to private transport) testing for interactions by time spent in the neighbourhood.

Primary outcome measure Minutes spent walking for transport per week.

Setting Toronto, Canada.

Participants Participants were aged 25 to 65 . The survey had a $72 \%$ response rate.

Results After adjusting for potential confounders, the walkability index was weakly associated with walking ( 1 SD of walkability score is associated with 0.25 more minutes walking/week, $\mathrm{p}<0.01$ ). Land-use mix was more strongly associated with walking than the walkability index. Time spent at the residential neighbourhood modified the relationship between land-use mix and transport-related walking in a dose-effect manner $(p<0.01)$, those spending 5 hours on average at their residential neighbourhood have $0.2 \mathrm{~min} /$ day more walking for each additional land-use mix score and those spending 12 hours have $0.5 \mathrm{~min} /$ day more walking for each additional land-use mix score.

Conclusions Our findings suggest that walkability is associated with increased walking time, but it is modified by time spent in the neighbourhood. Our study underscores the importance of testing 'time spent in the neighbourhood' as a modifier of environmental exposures in studies of environmental correlates of walking.
Strengths and limitations of this study

- Components of the walkability index are examined separately (ie, land-use mix, residential density and street connectivity) to better understand their relative importance as environmental correlate of walking for transport

- We investigated how time spent in one's home neighbourhood impacted the relationship between neighbourhood walkability and walking for transport, which was previously ignored

- The results reported here are based on cross-sectional data and do not account for potential reverse-causation

- Walking outcome was drawn from the validated International Physical Activity Questionnaire-12 survey rather than using accelerometer or global positioning system tracking

\section{INTRODUCTION}

Active transportation refers to human-powered means of travel, including walking for transport. There is evidence to suggest that health benefits exist for active transportation. For example, it may lead to a reduction in body mass index $(\mathrm{BMI})^{1}$ : in a stratified random cross-sectional sample of UK adults $(\mathrm{n}=7424)$, men who commuted via active transportation had 1.1 lower BMI scores (95\% CI 0.53 to 1.67 ) compared with those who use private modes of transport, and the impacts were also significantly associated for female active commuters $(0.72,95 \%$ CI 0.06 to 1.37$)$. A literature review of the health impacts of physical activity showed that walking one or more hours per week (either for leisure or transport) can significantly reduce the risk of cardiovascular disease, cancer, depression, diabetes, osteoporosis, obesity and 
hypertension. $^{2}$ In a systematic review of health impact assessments of active transport interventions, ${ }^{3}$ studies consistently report significant net health benefits of a mode shift to active transport, irrespective of geographical context or baseline setting. Benefits of active transportation also include economical and environmental benefits including savings in transport costs for residents living in walkable neighbourhoods, ${ }^{4}$ and reduction in vehicular emissions that is associated with decreases in years of life lost through ischaemic heart disease. ${ }^{5}$

Given the health and socioeconomic benefits, urban planners and public health practitioners have an immense interest in uncovering modifiable environmental factors that would encourage individuals to engage in walking for transport. Studies on adults walking for transport have drawn on the concept of neighbourhood walkability. This has been developed as an environmental index typically encompassing land-use mix, retail space, residential density and the connectivity of streets. ${ }^{6-8}$ For example, one such study shows that individuals living in areas that have high walkability (versus those in low walkability areas) spend around 30 min longer walking each week. ${ }^{9}$

\section{The temporal dimension of exposure to walkable environments}

There is growing evidence of the effect of walkability on active transport, including a systematic review showing that walkability indexes are consistently associated with physical activity for transport. ${ }^{10}$ However, this body of research is also characterised by a lack of consideration for individuals' duration of exposure to their neighbourhood context. By ignoring the temporal dimension of environmental exposure, previous studies may have introduced measurement bias because duration of exposure to the residential environments may be significantly different between participants. The problem of ignoring the temporal dimension of exposure has been highlighted in previous studies on neighbourhood effects on health. ${ }^{112}$ Accounting for duration of exposure to neighbourhood environments can reveal significant subgroup differences between those who spend varying amounts of time in their residential environments.

The 2010 Canadian General Social Survey highlights that time spent at home and residential neighbourhood differs significantly by age and income groups $(\mathrm{p}<0.01){ }^{13}$ Given the residential time use disparities, we hypothesise that individuals who spend more time in their residential neighbourhood would be more strongly affected by their residential neighbourhood walkability. In other words, a stronger association between neighbourhood walkability and walking for transport behaviour may exist for those who spend more time at their residential neighbourhood compared with those who spend less time there.

The primary aim of this study is to investigate potential model misclassification in previous studies of walkability by quantifying the temporal dimension of residential exposure through effect modification. In addition, our secondary aim is to improve the interpretability of the walkability index and improve its usefulness for informing active transport policies. By analysing components of the index separately (ie, land-use mix, residential density and street connectivity), we aim to shed light on their relative importance in relation to walking for transport. A comprehensive review of the association between walkability measures and active transport showed that 11 of 34 publications used walkability as an index. ${ }^{10}$ However, the review mentioned that using the full walkability index (without analysing its components) can be problematic since the various components of the index are mixed in and the strength of association for each component is not known. This reduces its usefulness at informing specific urban planning policies. Therefore, in this study, the full walkability index as well as its individual components will be examined.

To achieve these two aims, we asked the following three research questions:

1. Is there an association between the walkability index and self-reported walking for transport after adjusting for individual-level confounders?

2. What is the association between each of the three components of the walkability index (ie, land-use mix, residential density and road intersections density) and self-reported walking for transport after adjusting for individual-level confounders? (We acknowledge that there is already a strong body of research as it relates to questions 1 and 2; however, these are necessary intermediate questions as we work towards answering question 3 relating to modification of effect by exposure time, which is a novel contribution)

3. Is the strength of association between walkability and walking for transport different for people who spend differing amounts of time at their residential neighbourhoods?

\section{METHODS}

The project, Neighbourhood Effects on Health and Well-being (NEHW), was a cross-sectional study investigating the effects of neighbourhood characteristics on population health in Toronto, Canada. ${ }^{14}$ A three-staged sampling process was employed and a random sample of 50 Toronto neighbourhoods, represented by neighbourhood planning areas (NPAs), were chosen from a total of 140. NPAs are the official neighbourhoods of the city designated by the municipal government. Each NPA contained between 2 and 10 census tracts (CTs), of which 1 to 2 were randomly selected, returning 87 CTs. Finally, a random sample of individuals were selected within each CT, according to the address of residence. The target of 30 individuals per CT was reached in 51 of the 87 CTs, with a range from 9 to 31 individuals in total. See figure 1 for map of sampled CTs. The eligibility criteria were that one resident per household responded, was aged 25 to 65 , had lived in the neighbourhood for at least 6 months and could communicate in English. There was a response rate of 72\%, taken from March 2009 and June 2011. The 


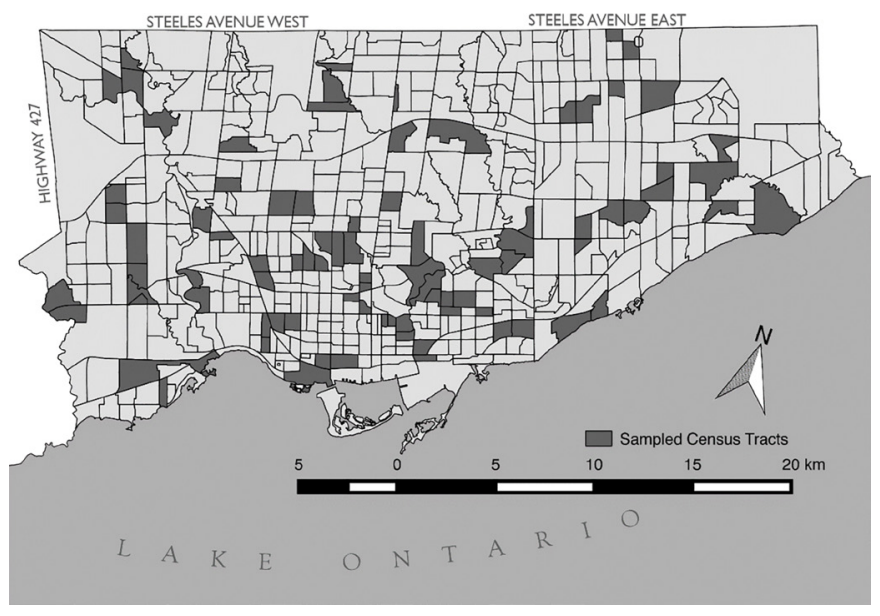

Figure 1 Map of the City of Toronto with the sampled 87 census tracts.

total number of individuals included is 2411 , who were interviewed in person. Written consent was provided at the time of the interview, and the ethics approval for this project was granted by the institutional review board of St. Michael's Hospital in Toronto, Canada.

To ensure that our sample represented the population of the City of Toronto, survey weights were created from the 2006 Canadian census data for the City of Toronto, which is a common practice in survey research. ${ }^{15}$ The data was weighted by the following socio-demographical characteristics: sex, household income, household size, immigrant status and age. These variables were chosen because descriptive analyses suggested that our sample was either over- or under-represented on each of these characteristics. To derive the NEHW weights, we constructed cross tabulations of the selected socio-demographical variables for our sample. The percentages for each combination were then compared with the percentage of the same combination of categories in the Canadian census data, based on a ratio. By constructing the weight in this way, we analytically placed more weight on the under-represented categories and less weight on over-represented cases.

\section{Patient and public involvement}

Patients and the public were not involved in the design and conduct of this study

\section{Dependent variable: walking for transport}

Questions on walking for transport were drawn from the International Physical Activity Questionnaire (IPAQ12): a survey instrument used to measure self-reported physical activity and inactivity in adults. ${ }^{16}$ The question for the walking outcome started with the prompt, "think only about walking you might have done to travel to and from work, to do errands or to go from place to place'. The interviewer then asked, " during the last 7 days, on how many days did you walk for at least $10 \mathrm{~min}$ at a time from place to place?'. If at least 1 day was spent walking for transport for $10 \mathrm{~min}$, then interviewer asked, 'how much time did you usually spend on one of those days walking from place to place?' with responses in hours and minutes. Total minutes of walking for transport was calculated by multiplying the number of days walked by the time spent walking and a daily average was computed by taking the weekly total and dividing it by seven.

\section{Walkability index}

The walkability index is typically comprised of several components including land-use mix, street connectivity and net residential density. ${ }^{17}$ There are a number of ways that land-use mix is measured including use of the entropy index, the dissimilarity index, distance to destinations and number of amenities available within a given sized buffer. ${ }^{18}$ Among these methods, the entropy index, which can be used to quantify the randomness, segregation and diversity of land-use mix within a given area, is the most widely accepted and commonly used. ${ }^{17-21}$ Based on the method adapted from Frank et al, we use the following land-use mix entropy index:

$$
\text { Land use mix entropy index }=-\sum_{j=1}^{6} \frac{P_{j} \times \log _{e}\left(P_{j}\right)}{\log _{e}(n 6)}
$$

where

- $\mathrm{P}_{\mathrm{j}}=$ the proportion of developed land (ie, building floor space area of $\mathrm{J}^{\text {th }}$ land-use type divided by building floor space area of all five land-use types).

- N6 = the number of land-uses ( $n=1$ through 6, summing the number of different land-uses present that is, single family residential, multifamily residential, commercial, office, industrial and green space).

The original entropy index from Frank et al examined a three-category mix of residential, commercial and office. For the purposes of this study, we expanded the land-use entropy index to describe the evenness of the distribution of built square footage among residential, commercial, office, industrial and green space. The entropy index varied between 0 and 1 , where 0 indicates a single use within a given CT, and 1 indicates the maximum amount of land-use mix in the CT. All addresses including land-use categories were extracted from the Toronto One Address Online Repository, ${ }^{22}$ and subsequently the point data was matched geographically to municipal Property Data Maps ${ }^{23}$ to ascertain building floor space area. Building floor space was calculated for all land-use types except green space. The second component of the walkability index, street connectivity, was obtained by calculating the number of road intersections per kilometre squared within a given CT using data from the Route Logistics dataset. ${ }^{24}$ Finally, net residential density was calculated by taking the 2006 census dwelling counts divided by the area of land in residential use. The area of land in residential use was calculated in Geographic Information System (GIS) by summing the area of all land parcels containing residential buildings within the CT, with the land parcel data from property data maps. ${ }^{23}$ All three components (ie, land-use mix, street connectivity and net residential density) were transformed into z-scores, and following 
Frank et al the walkability index is calculated as: $(6 * z$-score land-use mix) $+z$ score dwelling density and $+z$ score intersection density. High values on the index denote areas of higher walkability and lower values denote areas of lower walkability. All z-scores were computed based on the distribution of the City of Toronto.

\section{Time spent in their residential neighbourhood}

We used the 2010 Canadian general social survey (CGSS), which included detailed time-use dairies of 15390 Canadians, to estimate the time spent in residential neighbourhood of our sample using results from a multivariate regression model. This method to estimate time spent at the residential neighbourhood based on results of time-use diaries was used in previous studies. ${ }^{11} 12$ First, we extracted records for all participants aged 25 to 65 living in urban areas from the CGSS. Second, using CGSS data, time spent at the residential neighbourhood was modelled using the following predictor variables: age, education level, income, gender, marital status, having children under 5 years of age and minutes spent at work (away from home). All the above predictors were significantly associated with the time spent at the residential neighbourhood $(\mathrm{p}<0.01)$. The model had an adjusted $\mathrm{r} 2$ of 0.52. Beta-coefficients from the regression were used to estimate individual time spent at the residential neighbourhood for our sample. For example, starting with the intercept of $1287.15 \mathrm{~min}$ at the residential neighbourhood per day, (1) for every minute spent at work, 0.69 fewer minutes were spent at home, (2) females spent 39.14 more minutes at home compared with males, (3) persons with children under 5 years of age spent 31.22 more minutes compared with those without, etc. Lastly, we subtracted individuals' sleep duration time from the total time in the residential neighbourhood because individuals had no chance of interacting with their residential environment while sleeping. Sleeping information was obtained in our survey through a single item question 'How long do you usually spend sleeping each night (not including time spent resting in bed)?' Time spent in the residential neighbourhood is modelled as a continuous variable.

\section{Statistical methods}

Data from the survey was based on a stratified random sample where multiple individuals were sampled within the same neighbourhood (ie, average of 28 individuals per census tract across 87 tracts), which led to a spatially autocorrelated data structure unsuitable for typical regression techniques. Therefore, multilevel modelling was used to account for the lack of independence and to understand the associations between the predictors mentioned above and the walking outcome. ${ }^{25}$ The overall aims of the statistical models were to establish the independent association between the walkability index and walking for transport, progressively elaborate on the traditional walkability index by investigating the components of the index and how the concept of walkability interacted with
Table 1 Sociodemographical distribution of sample crosstabulated with minutes per day spent walking for transport

\begin{tabular}{|c|c|c|}
\hline & $\begin{array}{l}\text { Entire cohort } \\
\text { no. }(\% \text { of } \\
\text { sample) }\end{array}$ & $\begin{array}{l}\text { Mean minutes } \\
\text { per day spent } \\
\text { walking for } \\
\text { transport (SD) }\end{array}$ \\
\hline Participants & $2411(100)$ & $7.57(0.47)$ \\
\hline \multicolumn{3}{|l|}{ Age (quartiles) } \\
\hline Q1 25 to 36.8 & $605(25.1)$ & $7.49(0.94)$ \\
\hline Q2 36.9 to 43.1 & $627(26)$ & $9.09(1.33)$ \\
\hline Q3 43.2 to 52.7 & $578(24)$ & $6.87(0.49)$ \\
\hline Q4 52.8 to 65 & $601(24.9)$ & $7.04(0.66)$ \\
\hline \multicolumn{3}{|l|}{ Gender } \\
\hline Women & $1248(51.8)$ & $7.21(0.81)$ \\
\hline Men & 1163 (48.2) & $8.12(0.49)$ \\
\hline \multicolumn{3}{|l|}{ Total household income } \\
\hline$<=\$ 60000$ & $662(27.5)$ & $9.15(1.35)$ \\
\hline$\$ 60001$ to $\$ 113200$ & $735(30.5)$ & $7.06(0.52)$ \\
\hline$\$ 113201$ to $\$ 140000$ & $436(18)$ & $6.12(0.69)$ \\
\hline$>=\$ 140000$ & $578(24)$ & $7.54(0.73)$ \\
\hline \multicolumn{3}{|l|}{ Self-rated health } \\
\hline Excellent, very good, good & 2079 (86.2) & $8.5(0.9)$ \\
\hline Fair, poor & $332(13.8)$ & $6.0(1.1)$ \\
\hline \multicolumn{3}{|l|}{$\begin{array}{l}\text { Regularly use private } \\
\text { vehicles }\end{array}$} \\
\hline Yes & $1543(64)$ & $5.9(1.8)$ \\
\hline No & $868(36)$ & $10.2(2.4)$ \\
\hline
\end{tabular}

individual time use. All models described here included the following individual level covariates: gender (ie, male or female), age, household income, self-rated health (ie, excellent, very good, good, fair and poor) and regular use of private transport (ie, yes vs no). Model 1 investigated the independent association between the walkability index and walking for transport. For model 2, we examined walking for transport and the three components of the walkability index. For model 3, we retained only components of the walkability index that were significant from model 2 (ie, only land-use mix is significant at $\mathrm{p}<0.05)$ and time spent at the residential neighbourhood as a direct effect. In model 4 , we examined time spent at the residential neighbourhood and its interaction with land-use mix. Multilevel models (zero-inflated Poisson models) were performed in Rstudio V.1.0.136 using the lme4 package. We checked for multicollinearity in all models using calculations of the variance inflation factor where a ratio of 10 or above would indicate a problem. ${ }^{26}$

\section{RESULTS}

Of the 2411 participants, $51.8 \%$ were female, the mean age was 44 years, and the mean household income was $\$ 113$ 200. The mean time spent walking for transport was $7.57 \mathrm{~min}$ per day $(\mathrm{SD}=0.47)$. Table 1 shows the 
Table 2 Multilevel regressions for the walking outcome adjusting for age, gender, income, self-rated health and regular access to private mode of transport

\begin{tabular}{|c|c|c|c|c|}
\hline & $\begin{array}{l}\text { Model 1: } \\
\text { walkability index }\end{array}$ & $\begin{array}{l}\text { Model 2: } \\
\text { components of } \\
\text { the walkability } \\
\text { index }\end{array}$ & $\begin{array}{l}\text { Model 3: } \\
\text { land-use } \\
\text { mix + time use }\end{array}$ & $\begin{array}{l}\text { Model 4: } \\
\text { land-use mix } \\
\text { with time use } \\
\text { interaction }\end{array}$ \\
\hline & \multicolumn{4}{|c|}{ Minutes of walking for transport per day (SE) } \\
\hline Intercept & $1.317(0.175)^{\star \star \star}$ & $1.315(0.174)^{\star \star \star}$ & $1.426(0.133)^{\star \star *}$ & $1.515(0.126)^{\star \star \star}$ \\
\hline Walkability index (z-score) & $0.036(0.004)^{\star \star}$ & - & - & - \\
\hline Land-use mix (z-score) & - & $0.246(0.051)^{\star \star}$ & $0.231(0.051)^{\star \star}$ & $0.021(0.013)^{\star}$ \\
\hline Dwelling density (z-score) & - & $-0.011(0.051)$ & - & - \\
\hline Street connectivity (z-score) & - & $0.058(0.055)$ & - & - \\
\hline Time at home neighbourhood & & & $0.02(0.016)$ & $0.012(0.017)$ \\
\hline Land-use $\mathrm{mix}^{*}$ time at home neighbourhood & & & & $0.04(0.001)^{\star \star \star}$ \\
\hline
\end{tabular}

All models controlled for age, gender, income, self-rated health and have regular access to private transport.

${ }^{*} \mathrm{p}<0.05,{ }^{* *} \mathrm{p}<0.01,{ }^{* * *} \mathrm{p}<0.001$.

cross-tabulation between the walking outcome in minutes and sample characteristics. Readers may refer to a previous study for detailed information and the distributions of walkability and related built-environmental characteristics across City of Toronto. ${ }^{27}$

All regression models to follow have been adjusted for the effects of age, gender, income, self-rated health and regular access to private vehicles. For model 1 (see table 2), we found that a 1 SD increase in the z-score of walkability index is associated with 0.036 additional minutes of walking for transport per day $(\mathrm{p}<0.01)$.

In model 2 (where we included the three components of the walkability index as separate independent variables), only land-use mix was found to be significantly associated with walking for transport: $1 \mathrm{SD}$ increase in the z-score of land-use mix was associated with 0.246 additional minutes of walking for transport per day $(p<0.01)$. It should be noted that multicollinearity as a potential problem was checked and found not to be an issue: we found that variance inflation index ranged from 2.2 to 4.2, which sits below the recommended cut-off of 10 . Since land-use mix was the only significant factor for walking for transport of the index, a decision was made to only include the land-use mix component in subsequent models. In Model 3, we removed predictors that were not significant at $\mathrm{p}<0.05$ from the previous model (ie, dwelling density and street connectivity) and added the predictor for 'time spent in the residential neighbourhood' (as a direct effect). Previous results remained similar, and we found that time spent in the residential neighbourhood was not directly associated with the outcome.

In the final model 4, we found that time spent at the residential neighbourhood significantly modified the effects of land-use mix on walking for transport. Holding other covariates constant in the model, we would expect those spending 5 hours at the residential neighbourhood to have $0.2 \mathrm{~min} /$ day more walking for each additional land-use mix score, those spending 8 hours to have
$0.3 \mathrm{~min} /$ day more walking for each additional land-use mix score and those spending 12 hours to have $0.5 \mathrm{~min} /$ day more walking for each additional land-use mix score. See table 3 for the relationship between land-use mix and time spent walking for varying amounts of time spent in the residential neighbourhood.

\section{DISCUSSION}

This paper offers two unique insights into the study of walkability: first, our results challenge the suitability of the full walkability index (vs using components of the index) for predicting walking for transport; second, we show that by ignoring the temporal dimension of exposure to the neighbourhood, previous walkability studies may have misspecified models predicting walking for transport since they did not account for effect modification by time spent in the residential environment.

The walkability index had statistically significant but weak association with walking for transport. Multiplying daily average of $0.036 \mathrm{~min}$ by seven, we would expect only 0.25 additional minutes of walking per week for each SD increase in the z-score of the walkability index in model 1. Further analysis (in model 2) showed that this association

Table 3 Relationship between land-use mix and walking for individuals who spend varying amounts of time in their residential neighbourhoods

\begin{tabular}{ll}
$\begin{array}{l}\text { Time spent in } \\
\text { the residential } \\
\text { neighbourhood }\end{array}$ & $\begin{array}{l}\text { Additional minutes spent walking per } \\
\text { day for each 1 SD increase in land-use } \\
\text { mix score }\end{array}$ \\
\hline 3 hours & 0.12 extra min/per 1 SD in land-use mix \\
\hline hours & 0.2 extra min/per 1 SD in land-use mix \\
8 hours & 0.3 extra min/per 1 SD in land-use mix \\
12 hours & 0.5 extra min/per 1 SD in land-use mix \\
\hline 14 hours & 0.56 extra min/per 1 SD in land-use mix \\
\hline
\end{tabular}


is largely driven by the land-use mix component rather than dwelling density and street connectivity. Furthermore, taking land-use mix alone saw a stronger association with walking for transport. It should be noted that in bivariate correlations all three components of the walkability index were significantly associated with walking for transport ( $r=0.20$ to 0.38 , all at $p<0.01)$, but the associations for the last two components became non-significant at the $p<0.05$ level after multivariate adjustments. These results suggest that while the common walkability index (such as one used in Frank $e t a l$ ) may not always be suitable for predicting walking for transport in every urban setting, the components of the index may still yield useful information. Future analyses using the walkability index should examine whether each component within the index is meaningfully contributing to the overall performance of the walkability index in other cities.

To contextualise the real-world relevance of the results, it is useful to elaborate on the impact of land use by comparing the walking behaviour associated with living in low versus highly walkable neighbourhoods. Among those spending an average of 12 hours in their residential neighbourhood, those who live in highly walkable neighbourhoods (ie, scoring 95th percentile on land-use mix) are estimated to spend 12 min more per week walking for transport compared with those in the least walkable neighbourhoods (ie, scoring 5 th percentile on land-use mix). Given that participants report an average of $53 \mathrm{~min}$ on walking for transport per week, an addition of $12 \mathrm{~min}$ per week represents a 23\% increase. However, for those who spend an average of 5 hours at their residential neighbourhood, less than $10 \%$ difference (ie, $4.6 \mathrm{~min}$ ) is expected. While the association between land-use mix and any particular individual's walking behaviour is relatively small, the aggregate impact of land-use, which is the product of the effects of the environmental exposure and the number of persons affected, is of a magnitude that is relevant for city planning. In other words, while the effect sizes of environmental exposures are typically smaller than predictors at the individual level, their pervasiveness (and the potential for interventions through urban planning policies) broaden the scope of their relevance.

Our results are generally consistent with previous studies that found walkability indexes and land-use mix are correlated with measures of active transport reviewed above (also see Grasser et al's review on this subject ${ }^{10}$ ). However, our effects sizes are smaller than comparable studies. For example, Van Dyck et al reported that compared with residents of the least walkable neighbourhoods, residents of the most walkable neighbourhoods walked (for the purpose of transport), on average, $80 \mathrm{~min}$ more per week. ${ }^{28}$ Sallis $e t$ al found that residents of the most walkable neighbourhoods spent 31 more minutes walking for transport, compared with those living in the least walkable neighbourhoods. ${ }^{29}$ Further studies that involve comparisons across different contexts, including cities from Europe and North America, would be necessary to understand the factors that influence the effect size of walkability.

With regards to our main finding dealing with time interactions, previous studies of neighbourhood walkability have neglected to consider that individuals who spend varying amounts of time in their residential neighbourhood may be affected differently by their residential environment. This is the first study to demonstrate how the association between neighbourhood walkability and walking for transport is modified by individuals' time spent in their residential neighbourhood. We show that consideration of the temporal dimension of residential exposure is critically important in models predicting walking for transport. In the case of neighbourhood walkability, time spent at the residential neighbourhood modified the relationship between the walkability measure (ie, land-use mix) and walking behaviour in a dose-effect manner.

One of the limitations with this study was that the walking outcome were self-reported rather than measured objectively using an accelerometer or global positioning system tracking. There may be discrepancies between self-reported data and objective measures. However, self-reported walking times were drawn from the validated IPAQ-12 survey. The survey has been shown to have good retest reliability and convergent validity with walking data obtained objectively from accelerometers. ${ }^{16}$ Since the results reported here are based on cross-sectional data, they do not account for migration effects and neighbourhood self-selection bias (ie, people who already engage in walking for transport may choose to live in more walkable areas). Thus, results from this study could have overstated the environmental impacts on walking and cycling due to migration. Due to multicollinearity, we did not include education and occupational status as covariates into our models, but these may also be significant predictors for walking for transport. Lastly, we did not account for non-residential areas and activities (ie, the distance between home and work address, and influence of non-residential neighbourhoods, etc), which can significantly influence the amount of walking for transport. Further research using longitudinal data would be required to rule out migration as a factor and establish temporal order (ie, change in environment leading to change in behaviour) to establish evidence for causal link.

\section{CONCLUSIONS}

Based on our findings, we recommend that future studies on the effects of neighbourhood walkability should pay greater attention to individual time use and duration of exposure to the residential environment (ie, to test for interaction by duration of exposure). Our results highlight the importance of land-use mix in encouraging walking for transport, especially in areas where people spend significantly more time in their residential neighbourhoods. Neighbourhoods with a high proportion of low income families, unemployed people, people working 
from home and older adults are particularly vulnerable to the effects of not having a local walkable neighbourhood, since previous research have shown that these groups spend disproportionately greater time in their home and residential neighbourhood. ${ }^{30-32}$ Urban planning strategies that encourage the development of mixed use neighbourhoods could see an increase in the amount of walking for transport for these individuals, but would likely not increase transport-related walking for individuals who spend little time in their residential neighbourhoods (eg, high-income individuals, younger adults and those working long hours away from home). Our study underscores the importance of testing 'time spent in the neighbourhood' as a modifier of environmental exposures in studies of environmental correlates of walking (and more broadly including any related health outcomes). Since human environmental exposures are not limited to residential neighbourhoods, future research should consider both time use and walkability in residential and non-residential environments to capture the full impact of walkability/land-use mix across an individual's daily activity space.

Acknowledgements We thank Thomas Young for proofreading and editing the final draft of this paper.

Contributors AC wrote the main manuscript text, created main figures and tables, PA completed GIS and statistical analyses, P0 provided project funding, research advice and conceptualised project NEHW (Neighbourhood Effects on Health and Well-being). All authors reviewed the manuscript.

Funding This study was funded by Canadian Institutes of Health Research Grant MOP-84439 and the Social Science and Humanities Research Council Grant 410-2007-1499.

Competing interests None declared.

Patient consent for publication Obtained.

Ethics approval Ethics approval for this project was granted by the institutional review board of St Michael's Hospital in Toronto, Canada. Written consent from participants was provided at the time of the interview.

Provenance and peer review Not commissioned; externally peer reviewed.

Data sharing statement The datasets generated during and/or analysed during the current study are not publicly available due to confidentiality agreement with research participants, but are available from the corresponding author on reasonable request.

Open access This is an open access article distributed in accordance with the Creative Commons Attribution Non Commercial (CC BY-NC 4.0) license, which permits others to distribute, remix, adapt, build upon this work non-commercially, and license their derivative works on different terms, provided the original work is properly cited, appropriate credit is given, any changes made indicated, and the use is non-commercial. See: http://creativecommons.org/licenses/by-nc/4.0/.

\section{REFERENCES}

1. Flint E, Cummins S, Sacker A. Associations between active commuting, body fat, and body mass index: population based, cross sectional study in the United Kingdom. BMJ 2014;349:g4887.

2. Warburton DE, Nicol CW, Bredin SS. Health benefits of physical activity: the evidence. CMAJ 2006;174:801-9.

3. Mueller N, Rojas-Rueda D, Cole-Hunter T, et al. Health impact assessment of active transportation: A systematic review. Prev Med 2015;76:103-14.

4. McCann B. Surface Transportation Policy Project and the Center for Neighborhood Technology, Chapter Three. Driven to spend; the impact of sprawl on household transportation expenses, 2000.
5. Woodcock J, Edwards P, Tonne C, et al. Public health benefits of strategies to reduce greenhouse-gas emissions: urban land transport. Lancet 2009;374:1930-43.

6. Gebel K, Bauman A, Owen N. Correlates of non-concordance between perceived and objective measures of walkability. Ann Behav Med 2009;37:228-38.

7. Leslie E, Saelens B, Frank L, et al. Residents' perceptions of walkability attributes in objectively different neighbourhoods: a pilot study. Health Place 2005;11:227-36.

8. Owen N, Cerin E, Leslie E, et al. Neighborhood walkability and the walking behavior of Australian adults. Am J Prev Med 2007;33:387-95.

9. Saelens BE, Sallis JF, Frank LD. Environmental correlates of walking and cycling: findings from the transportation, urban design, and planning literatures. Ann Behav Med 2003;25:80-91.

10. Grasser G, Van Dyck D, Titze S, et al. Objectively measured walkability and active transport and weight-related outcomes in adults: a systematic review. Int J Public Health 2013;58:615-25.

11. Chum A, Farrell E, Vaivada T, et al. The effect of food environments on fruit and vegetable intake as modified by time spent at home: a cross-sectional study. BMJ Open 2015;5:e006200.

12. Chum A, O' Campo P. Contextual determinants of cardiovascular diseases: overcoming the residential trap by accounting for non-residential context and duration of exposure. Health Place 2013;24:73-9.

13. Statistics Canada. General Social Survey on Time Use: Overview of the Time Use of Canadians. 2010 http://publications.gc.ca/pub?id=9. $694622 \& \mathrm{sl}=0$.

14. O'Campo P, Wheaton B, Nisenbaum R, et al. The Neighbourhood Effects on Health and Well-being (NEHW) study. Health Place 2015;31:65-74.

15. Lohr S. Sampling: design and analysis: Duxbury Press, 1999.

16. Craig CL, Marshall AL, Sjöström M, et al. International physical activity questionnaire: 12 -country reliability and validity. Med Sci Sports Exerc 2003;35:1381-95.

17. Frank LD, Schmid TL, Sallis JF, et al. Linking objectively measured physical activity with objectively measured urban form: findings from SMARTRAQ. Am J Prev Med 2005;28:117-25.

18. Brown BB, Yamada I, Smith KR, et al. Mixed land use and walkability: Variations in land use measures and relationships with BMI, overweight, and obesity. Health Place 2009;15:1130-41.

19. Cervero R. Land use mixing and suburban mobility. Transportation Quarterly 1988;42:429-46.

20. Dur F, Yigitcanlar T. Assessing land-use and transport integration via a spatial composite indexing model. International Journal of Environmental Science and Technology 2015;12:803-16.

21. Booth GL, Creatore MI, Moineddin R, et al. Unwalkable neighborhoods, poverty, and the risk of diabetes among recent immigrants to Canada compared with long-term residents. Diabetes Care 2013;36:302-8.

22. City of Toronto. Address Points (Municipal) - Toronto One Address Repository. $2012 \mathrm{https} / / / w w w 1 . t o r o n t o . c a / w p s / p o r t a l / c o n t e n t o n l y ?$ vgnextoid=91415f9cd70bb210VgnVCM1000003dd60f89RCRD\& vgnextchannel=7807e03bb8d1e310VgnVCM10000071d60f89RCRD

23. City of Toronto. Property data maps. 2012 https://mdl.library. utoronto.ca/pdms/2013

24. DMTI Spatial Inc: DMTI Spatial, 2011.

25. Raudenbush SW, Bryk AS. Hierarchical linear models: applications and data analysis methods. 2nd edn: Sage, 2002.

26. Rogerson P. Statistical methods for geography: Sage, 2001.

27. Glazier RH, Creatore MI, Weyman JT, et al. Density, destinations or both? A comparison of measures of walkability in relation to transportation behaviors, obesity and diabetes in Toronto, Canada. PLoS One 2014;9:e85295.

28. Van Dyck D, Cardon G, Deforche B, et al. Neighborhood SES and walkability are related to physical activity behavior in Belgian adults. Prev Med 2010;50:S74-9.

29. Sallis JF, Saelens BE, Frank LD, et al. Neighborhood built environment and income: examining multiple health outcomes. Soc Sci Med 2009;68:1285-93.

30. Gershuny J. Time-use surveys and the measurement of national wellbeing: Centre for Time Use Research, University of Oxford, Swansea, UK, Office for National Statistics, 2011.

31. Leech JA, Nelson WC, BURNETT RT, et al. It's about time: A comparison of Canadian and American time-activity patterns. J Expo Sci Environ Epidemiol 2002;12:427-32.

32. Statistics Canada. Table 45-10-0002-01: General social survey (GSS), average time spent at various locations for the population aged 15 years and over, by population cohorts. 2015 https:// www150.statcan.gc.ca/t1/tbl1/en/tv.action?pid=4510000201 